\title{
Reducing the risk of importing pest-infested citrus by applying high pressure washing treatments offshore
}

\author{
M.J. Griffin ${ }^{1,2}$, S.R. Olsson ${ }^{1,2}$, L.E. Jamieson ${ }^{1,2}$, V. Kagy ${ }^{3}$, C. Mille ${ }^{3}$, P.G. Connolly ${ }^{1,2}$ and \\ A.B. Woolf ${ }^{1,2}$ \\ ${ }^{1}$ The New Zealand Institute of Plant E Food Research Limited, Private Bag 92169, \\ Auckland 1142, New Zealand \\ ${ }^{2}$ Better Border Biosecurity, www.b3nz.org \\ ${ }^{3}$ Agronomic Institute New Caledonia, Research Station for Fruit, Pocquereux, \\ B.P. 32-98880, La Foa, New Caledonia
}

\begin{abstract}
New Caledonia exports limes to New Zealand and Australia each year. In 2011, a high pressure washing (HPW) system was installed in an existing fresh lime grading line in La Tontouta, New Caledonia. Since then, fumigation of limes has decreased from 100\% of shipments prior to 2011 to 5.8\% in 2012 and 1.2\% in 2013 (from 173 and 82 shipments respectively). This paper reports on trials undertaken over the last 2 years while installing, modifying, testing and commercially operating the HPW system for lime exports. Fruit quality and removal of pests (mainly Glover's scale (Lepidosaphes gloverii) and mussel scale (Lepidosaphes beckii)) indicated that a 175 psi (1207 kPa) HPW treatment under a gantry of seven rows of two angled nozzles resulted in up to $97 \%$ removal of pests and $>84 \%$ of heavily infested limes being clean of pests, with no adverse effect on fruit quality.
\end{abstract}

Keywords insect removal, risk mitigation, quarantine, limes, scale insects.

\section{INTRODUCTION}

New Caledonia exports fresh limes to New Zealand and Australia from December to March each year. A range of insects that can cause market access issues occur on New Caledonian limes (Mille 2010). Scale are key pests, including Glover's scale (Lepidosaphes gloverii) and mussel scale ( $L$. beckii). Mealybugs are also important for cosmetic reasons, as some species contribute to large areas of sooty mould on fruit. In the past, the main pre-shipment treatment used on New Caledonia limes has been fumigation with methyl bromide. However, problems associated with methyl bromide include high toxicity to humans, ozone-depletion and adverse effects on fruit quality, so alternative disinfestation treatments are required. High-pressure washing (HPW) has been shown to remove a range of insect and mite pests (scale insect, mealybugs, leafroller egg rafts) from a range of fresh fruit commodities while maintaining fruit quality (citrus, avocados, capsicums, apples) (Honiball et al. 1979; Walker et al. 1996, 1999; Jamieson et al. 2000; Woolf et al. 2009; Jamieson et al. 2010). Exposed mealybugs and sooty mould are relatively easy to remove with high pressure washing (Whiting et al. 1998a), while the removal of scale insects is a greater challenge (Whiting et al. 1998b).

In New Caledonia prior to the HPW, limes were put into a water dump containing $2 \%$ sodium bicarbonate, then run along a $2 \mathrm{~m}$ rotating brush- 
bed with a light water spray and then waxed. Fruit were inspected before export and if infested with unwanted organisms were fumigated with methyl bromide. Generally, early season fruit have fewer insects and mites and require fewer fumigations, although most shipments of later harvests have required fumigation. Checks on 600 fruit per shipment are made by biosecurity staff. This number is divided equally among the different lime growers in the shipment. If insects/ mites are found on one grower's limes, then all the fruit from this grower are fumigated before they can be exported.

This paper reports on the results of various trials to decrease the use of methyl bromide fumigation of limes in New Caledonia. In 2011, collaboration between The New Zealand Institute for Plant \& Food Research Limited and Agronomic Institute New Caledonia resulted in a high pressure washer (HPW) system being installed in an existing fresh lime grading line in La Tontouta, New Caledonia. Water flow rate and pressure, speed of fruit over the brush bed, nozzle configuration and spray coverage combinations were tested to maximise disinfestation. In December of 2013, researchers from Plant \& Food Research returned to assess the functioning of the high pressure washer and further optimise it for insect removal from limes. This paper reports the results from these studies.

\section{MATERIALS AND METHODS \\ Design of a high pressure washing system for limes (2011 trials)}

Factors considered when designing this HPW system included: nozzle type, number of nozzles, nozzle layout over the brush bed, nozzle orientation (straight down or angled), nozzle height, brush bed type and speed, water pressure, treatment duration, and fruit rotation and orientation. The nozzle selected was the same as that used in most commercial apple washers in NZ $\left(\right.$ ProMax $^{\circledR}$ QuickJet ${ }^{\circledR}$ QPTA-15-40, New Zealand). The nozzle designation refers to a 15 litres/min flow rate and a $40^{\circ}$ angle spray pattern. HPW treatments were carried out using seven rows of two nozzles (14 in total) pointing alternately left and right, relative to the front of the washer, at an angle of $33^{\circ}$. The nozzles were aligned to point between the rollers of the brush bed and set at a height of $125 \mathrm{~mm}$ above the brushes.

A preliminary trial of insect removal from limes by high pressure washing was carried out in 2011 . Limes infested with scale insects or mealybugs were selected for HPW treatment ( $\mathrm{n}=118$ limes). The main area on the fruit where the insects were located was marked using a permanent marker pen and the total number of insects on the fruit recorded. Three treatments at 175 psi were run for 40,30 and $20 \mathrm{~s}$ with one replicate of 37-39 fruit for each treatment. Very heavily infested limes (more than 100 insects/fruit) were treated at 150 psi for $40 \mathrm{~s}(\mathrm{n}=4$ fruit). After treatment, the number of insects remaining on each fruit was counted, and the percentage removal calculated. Note that $1 \mathrm{psi}=6.895 \mathrm{kPa}$.

A larger trial was conducted in 2011 to determine insect removal at pressures of 0 (brush bed only, no water), 100, 125, 150 and 175 psi and various treatment times (10, 15, 20, 30 and $40 \mathrm{~s}$ ). There were three replicates of fruit (20 fruit per replicate) for each treatment and fruit were stored after treatment at either $10^{\circ} \mathrm{C}$ for 7 days or $20^{\circ} \mathrm{C}$ for 6 days. After storage the number of insects remaining was counted, and the percentage removal calculated for the treatment.

\section{Confirming results and optimising the washer (2013 trials)}

In 2013 four treatments were undertaken to test the efficacy of the commercial HPW used at La Tontouta to reduce pest infestation on limes and to test possible improvements to the HPW unit (Table 1). The main variables changed were the height of the gantry above the brush bed and the addition of "bumps" along the sides of the brush bed to create more movement (sideways rolling) of the limes, in the expectation that they are more likely to be pushed under the water spray (Figure 1). "Bars" were also added to make the brush bed narrower so that there were no dead spots where limes escaped a direct hit by water. The speed of the in-feed line was also increased to increase the throughput of limes under the nozzles. The distance from nozzle to output target was measured on an angle from the nozzle to a tennis ball. 


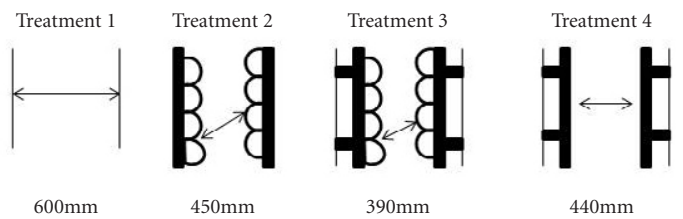

Figure 1 Diagram of the setup of the four treatments run in December 2013. Arrows indicate where the width measurements of the brush bed are taken from.

The removal of insects and kaolin clay/ PVA paint from limes was measured along with fruit quality for each treatment. Kaolin clay/PVA removal was used to visualise which parts of the limes were being hit by the water jets. Three replicate groups of 30 insectinfested and 30 painted limes were used for each treatment (treatments 1-3 only). Limes were harvested from growers in the northern regions of New Caledonia and transported to the pack house in La Tontouta. Limes from five different growers were randomly allocated to the different treatments. Fruit were examined before treatment and insect infested limes were given a unique number with the number and species of insects recorded for each lime. Tested fruit were collected in the water dump after HPW and reassessed, with the number of insects remaining on the fruit recorded. This trial was carried out towards the beginning of the lime season when insect infestation was low.

Fruit to be painted with kaolin clay/PVA mixture were warmed to ambient temperature and then dipped in a mixture of $4 \mathrm{~g}$ of PVA plus $20 \mathrm{~g}$ of kaolin clay in $100 \mathrm{ml}$ of water. These limes were dried overnight at ambient temperature, before treatment. After HPW treatment, painted fruit were visually assessed and the percentage of paint removed from the whole fruit and the percentage of paint removed from the stem end of the fruit (20 mm radius from the centre of the button (stem)) was recorded. The button was examined closely because this has been found to be the hardest place to remove insects from (V. Kagy, Agronomic Institute New Caledonia, personal communication).

To determine fruit quality responses to HPW, three replicate groups of 50 limes were exposed to HPW, waxed and dried before being boxed up and stored at $10^{\circ} \mathrm{C}$ for 10 days and then 7 days at $20^{\circ} \mathrm{C}$ to simulate shelf life.

For each replicate, limes were preloaded onto the in-feed rollers with five fruit before starting the washer. Experimental fruit was pushed through with filler fruit and once all the treatment fruit had passed through the water jets the remaining fruit were pushed out of the brush bed with a modified broom.

\section{Statistical analysis}

Using the MASS (Venables \& Ripley 2002) package with R (R Core Team 2014), negative binomial generalized linear models were used to model the numbers of scale insects present after treatment and percentage of fruit infested using discrete pressures as factor levels. The pressures and durations were shown to have independent effects with no interaction. A second model that included pressure as a continuous variable also showed no significant interaction between duration and water pressure. That model was used to calculate predicted numbers of scale over the ranges of pressure and duration used in

Table 1 Treatments carried out to determine the efficacy of the high pressure washing for the removal of insects and kaolin clay from export limes in New Caledonia during 2013.

\begin{tabular}{cccccc}
\hline Treatment & Bumps & $\begin{array}{c}\text { Brush bed } \\
\text { width }(\mathrm{mm})\end{array}$ & $\begin{array}{c}\text { Distance }- \\
\text { nozzle to } \\
\text { target }(\mathrm{mm})\end{array}$ & $\begin{array}{c}\text { Water pressure } \\
(\mathrm{psi})\end{array}$ & $\begin{array}{c}\text { Speed of limes } \\
\text { through } \\
\text { brush bed (s) }\end{array}$ \\
\hline 1 & No & 600 & 195 & 120 & $50-60$ \\
2 & Yes & 450 & 195 & 120 & $30-40$ \\
3 & Yes & 390 & 160 & 120 & $30-40$ \\
4 & No & 440 & 195 & 145 & $30-40$ \\
\hline
\end{tabular}


this study. By comparing those predictions with the numbers on the control fruit, the expected percentages of scale insects removed for all combinations of pressure and duration were calculated. A contour plot was used to show lines of constant percentage removal (Figure 2).

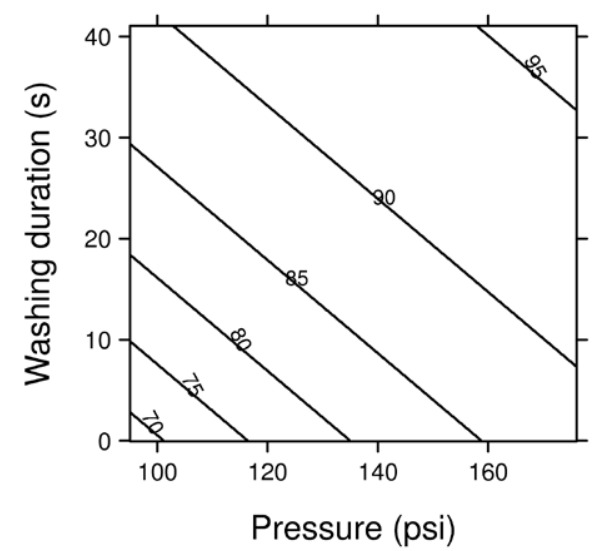

Figure 2 Contour plot output from model using pressure as a continuous variable showing lines of constant percentage removal. Standard error is ca $3 \%$ over the entire range.

\section{RESULTS}

\section{Design of a high pressure washing system for limes}

In the preliminary trial for 2011, the most prominent species found on the limes were Glover's and mussel scale insects (L. gloverii and L. beckii, respectively). All 175 psi treatments resulted in over $96 \%$ insect removal, with $97.6 \%$ of insects removed from limes that were heavily infested and treated with HPW at 150 psi (Table 2).
In the second trial of 2011, there was a significant reduction in the number of Lepidosaphes spp. found per fruit in all high pressure washing treatments relative to the unwashed control fruit (Figure 3) and scale insect removal rates improved with increasing pressure and duration (Figure 4). A model using the discrete pressures as factor levels indicated that the lowest pressure (100 psi) produced an overall reduction in scale numbers of about $75 \%$ and reduction in percentage of infested fruit of about $33 \%$. Increasing the pressure to 125 psi approximately halved the numbers again while further increases in pressure made minimal further reduction. Increasing the duration of the treatment showed an exponential reduction of $2.4 \%$ for each second of treatment in addition to the effect of the pressure. High pressure washing using $>130$ psi for 30 s removed $>90 \%$ of Lepidosaphes spp. from limes (Figure 2). There was no indication of a loss of commercial value of the limes after HPW and storage.

\section{Confirming results and optimising the washer (2013 trials)}

The number of insects remaining on the fruit after treatment were counted and recorded. A variety of insects were found on the limes in these treatments, including scale insects (Aonidiella aurantii, Unapsis citri, Lepidosaphes gloverii, Coccus viridis) and various species of mites and their eggs. The percentage of insects removed from the limes was slightly lower when the gantry was lowered (Treatment 3, Table 3). This may have been because the spray fans from the nozzles were narrower, which reduced the area of water impact on the fruit. Longer treatment

Table 2 Removal (\%) of insects from export limes using high pressure washing in New Caledonia during the preliminary trial in 2011.

\begin{tabular}{|c|c|c|c|c|c|}
\hline Treatment & $\begin{array}{l}\text { No. of } \\
\text { fruit }\end{array}$ & $\begin{array}{l}\text { No. of insects } \\
\text { before treatment } \\
\quad( \pm \text { SEM })\end{array}$ & $\begin{array}{c}\text { Average no. } \\
\text { of insects } \\
\text { per fruit }\end{array}$ & $\begin{array}{l}\text { No. of insects } \\
\text { after treatment }\end{array}$ & $\begin{array}{l}\text { Removal }(\%) \\
\text { based on total no. } \\
\text { insects }( \pm \text { SEM })\end{array}$ \\
\hline $175 \mathrm{psi} / 20 \mathrm{~s}$ & 38 & 374 & $9.80 \quad( \pm 1.54)$ & 13 & $96.5( \pm 0.79)$ \\
\hline $175 \mathrm{psi} / 30 \mathrm{~s}$ & 39 & 308 & $7.90 \quad( \pm 1.30)$ & 11 & $96.4( \pm 1.63)$ \\
\hline $175 \mathrm{psi} / 40 \mathrm{~s}$ & 37 & 352 & $9.50 \quad( \pm 1.86)$ & 0 & $100( \pm 0)$ \\
\hline $150 \mathrm{psi} / 40 \mathrm{~s}^{1}$ & 4 & 460 & $( \pm 29.77)$ & 11 & $97.6( \pm 0.93)$ \\
\hline
\end{tabular}

${ }^{1}$ Very heavily infested fruit. 


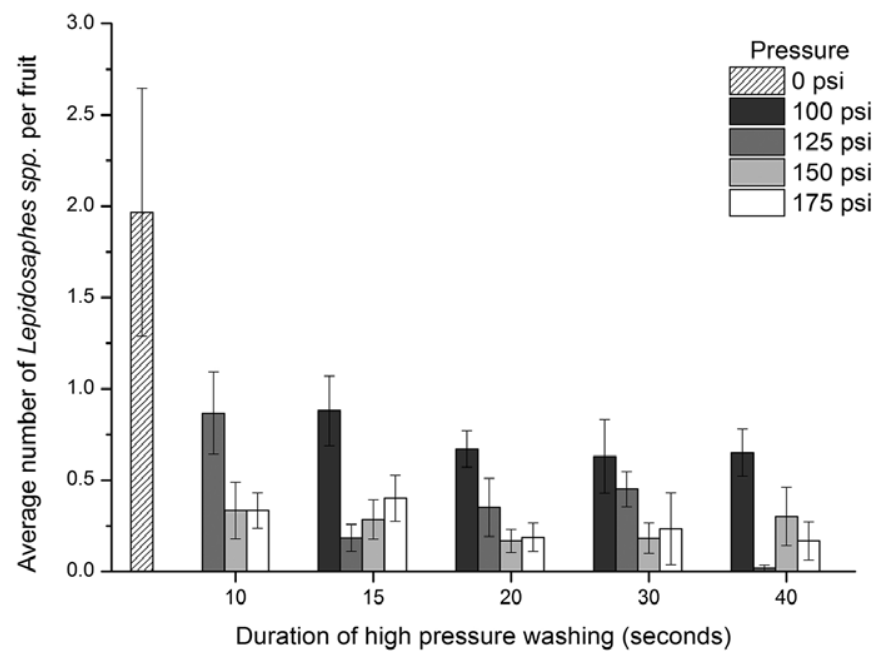

Figure 3 The average number of Lepidosaphes spp. per fruit following high pressure washing and storage for 7 days at $10^{\circ} \mathrm{C}$. Bars shown with \pm standard error of the mean.

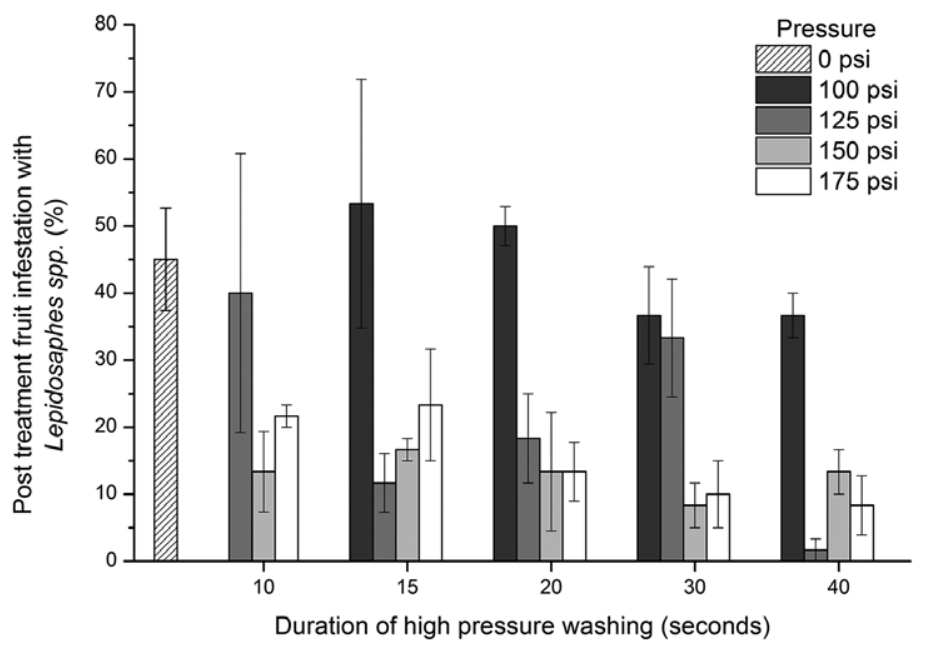

Figure 4 Percentage of Lepidosaphes spp. infested fruit in each treatment following high pressure washing and storage for 7 days at $10^{\circ} \mathrm{C}$. Bars shown with \pm standard error of the mean.

Table 3 Insect removal on export limes using high pressure washing. There were three replicates of insect-infested fruit for each treatment. The number of insects on each fruit was counted before and after treatment.

\begin{tabular}{cccccccc}
\hline & $\begin{array}{c}\text { No. of } \\
\text { Treatment } \\
\text { fruit }\end{array}$ & $\begin{array}{c}\text { Mefore } \\
\text { treatment }\end{array}$ & $\begin{array}{c}\text { Mean no. } \\
\text { of insects } \\
\text { per fruit }\end{array}$ & $\begin{array}{c}\text { No. of } \\
\text { insects } \\
\text { after } \\
\text { treatment }\end{array}$ & $\begin{array}{c}\text { Mean no. of } \\
\text { insects per } \\
\text { fruit after } \\
\text { treatment }\end{array}$ & $\begin{array}{c}\text { Percent } \\
\text { of infested } \\
\text { fruit after } \\
\text { treatment }\end{array}$ & $\begin{array}{c}\text { Total percent } \\
\text { removal of insects } \\
( \pm \text { SEM })\end{array}$ \\
\hline 1 & 85 & 546 & 6.42 & 12 & 0.14 & 9.4 & $97.8( \pm 6.88)$ \\
2 & 116 & 585 & 5.04 & 43 & 0.37 & 21.6 & $92.6( \pm 7.54)$ \\
3 & 161 & 636 & 3.95 & 98 & 0.61 & 14.3 & $84.6( \pm 8.12)$ \\
\hline
\end{tabular}


time (Treatment 1) may have contributed to insect removal being similar to when the bumps were added (Treatment 2).

Kaolin clay removal was increased with an increase in water pressure (Table 4). The increase in speed of the limes onto the brush bed increased the movement of limes as they are more likely to bump into each other and be moved under a nozzle spray.

Table 4 The average percentage of kaolin clay/ PVA removal from the surface of the limes and from the area around and under the button of the limes.

\begin{tabular}{lcc}
\hline Treatment & $\begin{array}{c}\text { Percent removed } \\
\text { from the surface } \\
\text { of the lime (\%) }\end{array}$ & $\begin{array}{c}\text { Percent removed } \\
\text { from the button } \\
\text { of the lime (\%) }\end{array}$ \\
\hline 1 & 97 & 84 \\
2 & 99 & 93 \\
3 & 99 & 95 \\
4 & 99 & 96 \\
\hline
\end{tabular}

Fruit quality was not adversely affected by HPW (data not shown).

\section{Impact on fumigation rates}

Since the installation of the high pressure washer in the packhouse in La Tontouta, fumigation of limes with methyl bromide before export has reduced markedly. Prior to the HPW being installed in 2011, 100\% of the shipments were fumigated before export (Table 5). This was reduced to $1.23 \%$ of the shipments ( 1 shipment) in 2013.

\section{DISCUSSION}

The installation of the high pressure washer system in the packhouse in La Tontouta, New Caledonia, greatly reduced the number of infested limes and, therefore, reduced the use of methyl bromide fumigation applied before the export of limes. The HPW system has had no noticeable impact on fruit quality. High pressure washing using $>130$ psi for 30 s removed $>90 \%$ of Lepidosaphes spp. from limes. This is comparable to other studies showing the removal of scale insects from citrus at $98-99.9 \%$ in a high pressure
Table 5 The number and percentage of fumigations of export lime shipments before and after the installation of the high pressure washer in 2011.

\begin{tabular}{lccc}
\hline Year & $\begin{array}{c}\text { Number of } \\
\text { shipments }\end{array}$ & $\begin{array}{c}\text { Number of } \\
\text { fumigations }\end{array}$ & $\begin{array}{c}\% \\
\text { fumigations }\end{array}$ \\
\hline 2005 & 17 & 17 & 100 \\
2006 & 103 & 103 & 100 \\
2007 & 98 & 98 & 100 \\
2008 & 229 & 229 & 100 \\
2009 & 89 & 89 & 100 \\
2010 & 132 & 132 & 100 \\
2011 & 79 & 34 & 43.04 \\
2012 & 173 & 10 & 5.78 \\
2013 & 82 & 1 & 1.23 \\
\hline
\end{tabular}

washing system (Walker et al. 1996; Walker et al. 1999). Other insects are relatively easy to remove with up to $99.9 \%$ removal of leafroller egg raft from 'Hass' avocados (Jamieson et al. 2000) and up to $100 \%$ removal of thrips, springtails and mites from kiwifruit (Whiting et al. 1998b).

Incidence of pests can be significantly reduced by HPW but not eliminated. Based on a compliance model (N. De Silva \& L.E. Jamieson, Plant \& Food Research, unpublished data), for a line of fruit that was $5 \%$ or $10 \%$ infested with an average of one pest per infested fruit, then 90 or $95 \%$ pest removal would be required to pass a 600 fruit sample with 95\% confidence. HPW will need to be applied with other risk mitigation measures such as pesticidal applications (e.g. oil) and fruit thinning in orchards, and other postharvest processes such as a postharvest dip/drench or coolstorage (De Lima et al. 2007). Increasing the throughput speed and adding bumps and bars to increase movement under the nozzles and reduce dead space neither enhanced nor reduced removal of scale insects.

Future research should focus on combining HPW with other risk mitigation measures as part of a systems approach to control regulated organisms on fruit (Jamieson et al. 2013). Limes are coolstored for 7-10 days after packing and during transport, therefore it would be prudent to include the impact that coolstorage has on pest 
and disease organisms into a systems approach along with the other pest and disease control strategies used for limes. Future research should focus on defining pest responses to these risk mitigation strategies applied as an integrated pest management system and fruit quality responses.

\section{ACKNOWLEDGEMENTS}

The authors would like to acknowledge funding from the Ministry of Business, Innovation and Employment via Better Border Biosecurity (B3; www.b3nz.org). Thank you to Nicolas Hugot of Arbofruits and the packhouse and export managers at La Tontouta for their support; technical staff of Agronomic Institute New Caledonia for their assistance; Asha Chhagan and Natalie Page-Weir for their comments on the paper; and Alex Wilson for her technical assistance.

\section{REFERENCES}

De Lima CPF, Jessup AJ, Cruickshank L, Walsh CJ, Mansfield ER 2007. Cold disinfestation of citrus (Citrus spp.) for Mediterranean fruit fly (Ceratitis capitata) and Queensland fruit fly (Bactrocera tryoni) (Diptera: Tephritidae). New Zealand Journal of Crop and Horticultural Science 35: 39-50. DOI: 10.1080/01140670709510166.

Honiball F, Giliomee JH, Randall JH 1979. Mechanical control of red scale (Aonidiella auranti Mask) on harvested oranges. Citrus and Subtropical Fruit Journal 549: 17-18.

Jamieson L, Whiting DC, Woolf AB, White A, McDonald RM 2000. Water-blasting avocados to remove leafroller eggs. New Zealand Plant Protection 53: 371-374.

Jamieson LE, Page-Weir NEM, Chhagan A, Olsson S, Connolly PG, McDonald RM, Woolf A 2010. High pressure water-washing to remove pests from capsicums. New Zealand Plant Protection 63: 118-122.

Jamieson LE, DeSilva HN, Worner SP, Rogers DJ, Hill MG, Walker JTS 2013. A review of methods for assessing and managing market access and biosecurity risks using systems approaches. New Zealand Plant Protection 66: 1-9.
Mille C 2011. Animaux nuisibles et utiles des jardins et vergers de Nouvelle Calédonie. Editions SENC, Entomological Society of New Caledonia. 200 p.

R Development Core Team 2012. R: A language and environment for statistical computing. $\mathrm{R}$ Foundation for Statistical Computing, Vienna, Austria. ISBN 3-900051-07-0, URL http://www.R-project.org/.

Venables WN, Ripley BD 2002. Modern Applied Statistics with S. Fourth Edition. Springer, New York. 495 p. ISBN 0-387-95457-0.

Walker G, Morse N, Arpaia ML 1996. Evaluation of a high-pressure washer for postharvest removal of California red scale (Homoptera: Diaspididae). Journal of Economic Entomology 89: 148-155.

Walker G, Zareh N, Arpaia ML 1999. Effect of pressure and dwell time on efficiency of a high-pressure washer for postharvest removal of California red scale (Homoptera: Diaspididae) from citrus fruit. Journal of Economic Entomology 92: 906-914.

Whiting D, Hoy L, Maindonald J, Connolly P, McDonald R 1998a. High-pressure washing treatments to remove obscure mealybug (Homoptera: Pseudococcidae) and lightbrown apple moth (Lepidoptera: Tortricidae) from harvested apples. Journal of Economic Entomology 91: 1458-1463.

Whiting D, Hoy LE, Connolly PG, McDonald RM 1998b. Effects of high-pressure water jets on armoured scale insects and other contaminants of harvested kiwifruit. Proceedings of the 51st New Zealand Plant Protection Conference: 211-215.

Woolf A, Olsson S, McDonald R, White A, Rogers D, Jamieson L 2009. Novel high pressure water-washing (or water blasting) for market access. Postharvest Pacifica 2009: Australasian Postharvest and Managing Quality in Chains Conference. p. 48. 